\title{
Antioxidant Activity and Initation Test of Extracts Obtained from Angelica dahurica
}

\author{
Yang-Suk Lee and Nam-Woo Kim ${ }^{\dagger}$ \\ Department of Herbal Biotechnology, Daegu Haany University, Gyeongbuk 712-715, Korea
}

\begin{abstract}
In this study, we assessed the free radical scavenging and xanthine oxidase inhibitory activities of extracts isolated from the dried roots and stems (including leaves) of Angelica dahurica. The initation response from these extracts was also assessed to determine potential cosmetic use. Both sources of $A$. dahurica extracts exhibited radical scavenging properties to different extents. The free radical scavenging potency $\left(\mathrm{EC}_{50}\right)$ of the stems (including leaves) of $A$. dahurica was $243.33 \mu \mathrm{g} / \mathrm{mL}$, which is significantly lower $(p<0.01)$ than that observed of the roots $(1,161.79$ $\mu \mathrm{g} / \mathrm{mL}$ ). The inhibition values $\left(\mathrm{EC}_{50}\right)$ of xanthine oxidase were as follows: $435.19 \mu \mathrm{g} / \mathrm{mL}$ (roots) and 434.66 $\mu \mathrm{g} / \mathrm{mL}$ (stems). We noted no significant differences between the two plant parts with regard to ability to inhibit xanthine oxidase activity. After the application of $A$. dahurica extracts to rabbits for skin and eye initation tests, no negative effects were observed; therefore, the extracts are considered to be non-initating to the skin and eye.
\end{abstract}

Key words: Angelica dahurica, antioxidant, irritation, free radical scavenging, xanthine oxidase inhibition

\section{INTRODUCTION}

Many plants have been extensively utilized as biological materials for food and natural products, and chemicals from plants have been isolated in many searches for new compounds for the treatment of diseases, as well as for functional foods and cosmetics (1). As a source for a variety of cosmetics, the plant products are often formulated as hot water extracts, displaying some pharmacological activity and no toxicity.

A. dahurica is a perennial herb that grows to a height of $2.5 \mathrm{~m}$. The plant is characterized by a hollow stem, large three-branched leaves, and umbels bearing many white flower heads. The plant grows wild in thickets located in China, Japan, Korea, and Russia. The roots have been identified as containing a sweat-inducing agent, which is capable of countering harmful external influences on the skin, including cold, heat, dampness, and dryness (2). A. dahurica and its extracts have also been proven to be effective in the treatment of skin ailment (acne, psoriasis), erythema, headache, toothache, sinusitis, colds, flu and excessive leukorrhea (2-4). According to the results of a recent study, extracts of this plant can protect against dexamethasone-induced disorders, and have also been shown to exhibit liver-protective activity, antimicrobial activity $(5,6)$, anti-inflammatory activity, and antimutagenic activity (7). Over twenty coumarins and furanocoumarins, including coumarin, scopoletin, psoralen, xanthotoxin, bergapten, and imperatorin have been isolated from A. dahurica (8-10).
In this study, we evaluated the free radical scavenging activity and xanthine oxidase inhibitory activity of the dried roots and stems (including leaves) of $A$. dahurica, as well as its potential irritability to the skin and eyes.

\section{MATERIALS AND METHODS}

\section{Extract preparation}

The dried roots and stem parts (including leaves) of A. dahurica $(100 \mathrm{~g})$ were cut into small pieces and successfully extracted with $1,000 \mathrm{~mL}$ of $70 \%$ methanol-water solution $\left(\mathrm{MeOH}-\mathrm{H}_{2} \mathrm{O}\right)$. The organic solvent was concentrated to yield the $\mathrm{MeOH}-\mathrm{H}_{2} \mathrm{O}$ extracts.

\section{Assays for DPPH radical scavenging activity}

The DPPH radical scavenging activity was measured by the method of Yang et al. (11), with slight modification. The $\mathrm{MeOH}-\mathrm{H}_{2} \mathrm{O}$ extracts were initially dissolved in $1 \mathrm{~mL}$ of deionized water (DDW) followed by dilution with DDW to prepare trial samples of different concentrations. The free radical scavenging activities of the roots and stems (including leaves) of A. dahurica were measured as follows. The reaction mixture contained $1 \mathrm{~mL}$ of $0.5 \mathrm{mM}$ DPPH-ethanol solution, $0.9 \mathrm{~mL}$ of $10 \mathrm{mM}$ acetate buffer (pH 5.6) and $0.1 \mathrm{~mL}$ of either test sample at different concentrations or deionized water (control). The mixture was allowed to react at room temperature for 20 minutes, and the absorbance values were evaluated at $517 \mathrm{~nm}$ and converted into percentage antioxidant activity, and that of the samples was expressed as the percentage decrease in absorbance as compared 
with the controls. The experiments were conducted in triplicate.

\section{Xanthine oxidase inhibition assays}

Xanthine oxidase activity was evaluated on the basis of uric acid formation from xanthine (12). The $\mathrm{MeOH}-$ $\mathrm{H}_{2} \mathrm{O}$ extracts were initially dissolved in $1 \mathrm{~mL}$ of methanol (95\%) followed by dilution with $0.1 \mathrm{mM}$ phosphate buffer ( $\mathrm{pH}$ 7.4) in order to prepare trial samples of different concentrations. The xanthine oxidase inhibition activities of the roots and stems (including leaves) of $A$. dahurica were measured as follows. The reaction mixtures containing $100 \mu \mathrm{L}$ of xanthine water solution (1.286 $\mathrm{mM}), 40 \mu \mathrm{L}$ of xanthine oxidase solution (0.0741 units/ $\mathrm{mL}$ ), $100 \mu \mathrm{L}$ of sample, and phosphate buffer for adjustment of the final volume to $2 \mathrm{~mL}$. The inhibition of xanthine oxidase activity was evaluated via the measurement of the formation of uric acid from xanthine with a spectrophotometer at $295 \mathrm{~nm}$ for $3 \mathrm{~min}$. Reaction mixture without sample was measured as a control, and ascorbic acid was utilized as a standard material. Xanthine oxidase inhibition was calculated using the following equation: Inhibition $(\%)=($ absorbance of control - absorbance of sample)/ absorbance of control $\times 100 \%$. The experiment was conducted in triplicate.

\section{Primary skin initation study in rabbits}

Four adult rabbits (male) of the New Zealand strain, weighing 1.50 to $2.05 \mathrm{~kg}$, were selected for each of the trial samples. Prior to dosing, the application sites were prepared by clipping the hair from the saddle areas of the rabbits. Two abraded areas located diagonally on the skin of each rabbit were prepared via the cutting of minor epidermal incisions with a hypodermic needle. $\mathrm{MeOH}-\mathrm{H}_{2} \mathrm{O}$ extracts of roots and stems (including leaves) of $A$. dahurica were dissolved in DDW in order to prepare sample solutions of $50 \mathrm{mg} / \mathrm{mL}$. The samples were then applied in a quantity of $0.5 \mathrm{~mL}$ under a 2-squarecentimeter surgical gauze patch on an area of intact skin and an area of abraded skin on each of the rabbits, and $0.5 \mathrm{~mL}$ DDW was also applied under gauze patches on other areas of the skin, serving as a control. After the application of the patches, the trunks of each rabbit were wrapped with bandages. The animals were restrained for $24 \mathrm{hr}$. At the end of the exposure period, the patches were removed and the reactions were immediately scored.

\section{Ocular initation study in rabbit}

Four adult rabbits (male) of the New Zealand strain, weighing 1.50 to $2.05 \mathrm{~kg}$ were selected for each of the trial samples. $\mathrm{MeOH}-\mathrm{H}_{2} \mathrm{O}$ extracts of the roots and stems (including leaves) of $A$. dahurica were dissolved in
DDW in order to prepare sample solutions of $50 \mathrm{mg} / \mathrm{mL}$. $0.1 \mathrm{~mL}$ of sample solution was applied to the conjunctival sac of the left eye of each of the test rabbits, and $0.1 \mathrm{~mL}$ of DDW was applied to the right eye, serving as a control. The upper and lower eyelids were then held together gently for a few seconds, then released. The treated eyes of the two rabbits were flushed with DDW after 30 seconds. Examinations for gross signs of eye irritation were conducted at $1,2,3,5$, and 7 days after application.

\section{Statistical analysis}

All data were expressed as the means \pm SD. The statistical analysis was performed using Statistical Package for the Social Science version 17.0 for Windows (SPSS INC, Chicago, IL, USA). Probability values $<0.01$ were student's $t$-test, significantly different compared between two trial groups.

\section{RESULTS}

\section{Assays for DPPH radical scavenging activity}

The DPPH radical scavenging activity of $A$. dahurica was examined at five different concentrations $(100,250$, 500, 1,000 and 2,000 $\mu \mathrm{g} / \mathrm{mL}$ ) as shown in Table 1. All A. dahurica extracts evidenced radical scavenging properties to a different extent, and DPPH radical formation was gradually reduced with increases in the concentration of A. dahurica. When the concentrations required to inhibit DPPH radical formation by $50 \%\left(\mathrm{EC}_{50}\right)$ were assessed, the free radical scavenging potency of the stems (including leaves) of $A$. dahurica was 243.33 $\mu \mathrm{g} / \mathrm{mL}$, which is significantly lower $(\mathrm{p}<0.01)$ than that observed in the roots $(1,161.79 \mu \mathrm{g} / \mathrm{mL})$. These results showed that both the dried roots and stems (including leaves) of $A$. dahurica evidence free radical scavenging activity, and that of the stems is more powerful.

Table 1. Free radical scavenging activity of $A$. dahurica

\begin{tabular}{ccc}
\hline \multirow{2}{*}{$\begin{array}{c}\text { Concentration } \\
(\mu \mathrm{g} / \mathrm{mL})\end{array}$} & \multicolumn{2}{c}{$\begin{array}{c}\text { Free radical scavenging activity } \\
\text { of } A \text {. dahurica }(\%)\end{array}$} \\
\cline { 2 - 3 } & Roots & $\begin{array}{c}\text { Stems } \\
\text { (including leaves) }\end{array}$ \\
\hline 0 & 0 & 0 \\
100 & $3.92 \pm 0.41$ & $24.22 \pm 0.16$ \\
250 & $9.46 \pm 0.13$ & $60.36 \pm 2.46$ \\
500 & $19.55 \pm 0.59$ & $73.09 \pm 4.37$ \\
1,000 & $39.06 \pm 0.81$ & $73.13 \pm 0.85$ \\
2,000 & $75.31 \pm 1.91$ & $74.00 \pm 0.25$ \\
\hline $\mathrm{EC}_{50}(\mu \mathrm{g} / \mathrm{mL})$ & $1,161.79 \pm 43.23$ & $243.33 \pm 24.15^{* *}$ \\
\hline
\end{tabular}

Values represent the mean \pm SD of 3 independent experiments. ${ }^{* *} \mathrm{p}<0.01$ (Student's $t$-test), significantly different compared between two trial groups. $\mathrm{EC}_{50}$ values were determined by linear regression analysis. 
Table 2. The inhibition of activity of roots and stems of $A$. dahurica on xanthine oxidase

\begin{tabular}{ccc}
\hline $\begin{array}{c}\text { Concentration } \\
(\mu \mathrm{g} / \mathrm{mL})\end{array}$ & \multicolumn{2}{c}{ Inhibition of xanthine oxidase (\%) } \\
\cline { 2 - 3 } & Roots & Stems (including leaves) \\
\hline 0 & 0 & 0 \\
25 & $3.93 \pm 1.43$ & $7.87 \pm 3.27$ \\
50 & $7.49 \pm 4.04$ & $17.53 \pm 3.27$ \\
125 & $23.10 \pm 8.88$ & $28.98 \pm 10.95$ \\
250 & $47.94 \pm 6.91$ & $35.03 \pm 7.87$ \\
500 & $54.90 \pm 9.34$ & $50.50 \pm 6.50$ \\
750 & $57.68 \pm 6.56$ & $88.31 \pm 11.00$ \\
\hline $\mathrm{EC}_{50}(\mu \mathrm{g} / \mathrm{mL})$ & $435.19 \pm 145.46$ & $434.66 \pm 175.37$ \\
\hline
\end{tabular}

Values represent the mean \pm SD of 3 independent experiments. $\mathrm{EC}_{50}$ values were determined by linear regression analysis.

\section{Xanthine oxidase inhibition assays}

The effects of $A$. dahurica on the inhibition of xanthine oxidase were assessed at six different concentrations, as is shown in Table 2. All A. dahurica extracts displayed inhibition activities on xanthine oxidase to different extents, and the formation of uric acid from xanthine declined gradually with increases in the concentration of $A$. dahurica. The dried roots of A. dahurica inhibited xanthine oxidase activity by $50 \%\left(\mathrm{EC}_{50}\right)$ at a concentration of $435.19 \mu \mathrm{g} / \mathrm{mL}$, and that of the stems (including leaves) was $434.66 \mu \mathrm{g} / \mathrm{mL}$. No significant differences were observed between the two plant parts on the inhibition of xanthine oxidase activity.

\section{Primary skin irritation study in rabbit}

All animals survived for the duration of the study, and all evidenced gains in body weight. No overt signs of toxicity were observed in any of the rabbits during the course of the study (Table 3). After the application of $A$. dahurica to rabbits, light yellow staining was observed at the treated skin sites, which did not affect the evaluation of skin responses. The control sites evidenced no response to the control procedure. No edema, erythema, or eschar formation was observed in any of the rabbits (Table 4). Therefore, A. dahurica was considered to be a non-irritant to the skin.

\section{Ocular initation study in rabbit}

After the application of the samples to rabbit eyes (ocular membrane), all of the rabbit eyes were normal. No abnormal changes, such as lacrimation, reddening, swelling, or pus formation were observed for up to 7
Table 4. Effect of roots and stems of A. dahurica on skin irritation in rabbit

\begin{tabular}{lccc}
\hline \multirow{2}{*}{ Reaction } & & \multicolumn{2}{c}{ A. dahurica } \\
\cline { 3 - 4 } & DDW & Roots & $\begin{array}{c}\text { Stems } \\
\text { (including leaves) }\end{array}$ \\
\hline Edema & 0 & 0 & 0 \\
Erythema & 0 & 0 & 0 \\
Atonia & 0 & 0 & 0 \\
Desquamation & 0 & 0 & 0 \\
Hecrosis & 0 & 0 & 0 \\
Coriaceousness & 0 & 0 & 0 \\
Fissuring & 0 & 0 & 0 \\
\hline
\end{tabular}

days after exposure (Table 5). Therefore, A. dahurica was considered to be a non-irritant to the eye.

\section{DISCUSSION}

Free radicals, which are powerful oxidants, are species that harbor unpaired electrons. They are generated in a host of bioorganic redox processes, may induce oxidative damage in various body components (e.g., lipids, proteins, nucleic acids, and saccharides) and may also be involved in processes resulting in the formation of mutations (13). Furthermore, radical reactions appear to perform a significant function in the development of chronic diseases including cancer, hypertension, cardiac infarction, arteriosclerosis, rheumatism, and cataracts (14). Free radicals may also constitute a contributory factor in a progressive decline in immune system function (15). Cooperative defense systems that protect the body against free radical damage include antioxidant nutrients and enzymes (16). One important way that the body is protected against oxidative stress via an increase in antioxidant levels (13). Therefore, the evaluation of the antioxidative properties of some materials, which are candidates for the prevention of oxidative damage, remains a highly active area of research. DPPH is a stable free radical, which is frequently utilized in evaluations of the antioxidant activity of several natural compounds (17). Antioxidants, upon interaction with DPPH, transfer electrons or hydrogen atoms to $\mathrm{DPPH}$, thus neutralizing its free radical character. Xanthine oxidase (XO) is the enzyme responsible for the formation of uric acid from the purines, hypoxanthine and xanthine, and is responsible for the medical condition referred to as gout. Gout

Table 3. Clinical observations

\begin{tabular}{|c|c|c|c|c|c|c|}
\hline \multirow{2}{*}{ A. dahurica } & \multirow{2}{*}{$\begin{array}{l}\text { Dosage } \\
(\mathrm{mg} / \mathrm{mL})\end{array}$} & \multirow{2}{*}{$\mathrm{N}$} & \multicolumn{2}{|c|}{ Body weight $(\mathrm{kg})$} & \multirow{2}{*}{ Weight gain $(\mathrm{kg})$} & \multirow{2}{*}{ Signs of toxicity } \\
\hline & & & Day 0 & Day 3 & & \\
\hline Roots & 50 & 4 & $1.78 \pm 0.389$ & $1.88 \pm 0.389$ & $0.10 \pm 0.000$ & None \\
\hline Stems & 50 & 4 & $1.78 \pm 0.177$ & $1.80 \pm 0.212$ & $0.03 \pm 0.035$ & None \\
\hline
\end{tabular}

Values represent the mean $\pm \mathrm{SD}$. 
Table 5. Effect of roots and stems of $A$. dahurica on eye irritation in rabbit

\begin{tabular}{lcccccc}
\hline & & \multicolumn{3}{c}{ A. dahurica } \\
\cline { 3 - 4 } Organs & DDW & \multicolumn{2}{c}{ Roots } & & \multicolumn{2}{c}{ Stems (including leaves) } \\
\cline { 3 - 4 } \cline { 5 - 7 } & & Washing group & No washing group & & Washing group & No washing group \\
\hline Corneal & 0 & 0 & 0 & 0 & 0 \\
Iris & 0 & 0 & 0 & 0 & 0 \\
Conjunctival & 0 & 0 & 0 & 0 & 0 \\
Edema & 0 & 0 & 0 & 0 & 0 \\
\hline
\end{tabular}

is induced by the deposition of uric acid in the joints, resulting in painful inflammation, with XO inhibition resulting in a remission in gout (18). XO also functions as an important biological source of oxygen-derived free radicals, which contribute to oxidative damage to living tissues that are involved in a variety of pathological processes, including inflammation, atherosclerosis, cancer, and aging (19). XO inhibitors may potentially prove useful for the treatment of gout or other XO-induced diseases (20).

The free radical scavenging and antioxidant activity observed in A. dahurica may be associated with certain of its compounds. Piao et al. (21) isolated 11 furanocoumarins from the roots of A. dahurica. Two of them, 9-hydroxy-4-methoxypsoralen and alloisoimperatorin, displayed profound radical scavenging properties, whereas the other nine furanocoumarins had only minimal activities.

In the current study, the roots and stems (including leaves) were determined to exert potent antioxidant effects against the DPPH radical and xanthine oxidase.

Additionally, according to the results of the primary skin irritation and ocular irritation tests, A. dahurica was determined to be non-irritating to the skin and eye at a concentration of $50 \mathrm{mg} / \mathrm{mL}$.

\section{REFERENCES}

1. Nguyen MT, Awale S, Tezuka Y, Tran QL, Watanabe H, Kadota S. 2004. Xanthine oxidase inhibitory activity of Vietnamese medicinal plants. Biol Pharm Bull 27: 14141421.

2. Kimura T, But PPH, Guo JX, Sung CK. 1996. International collation of traditional and folk medicine, Part 1. World scientific, Singapore. p 117-118.

3. Koo J, Arain S. 2003. Traditional Chinese medicine in dermatology. Clin Dermatol 17: 21-27.

4. Tang W, Eisenbrand G. 1992. Chinese drugs of plant origin, chemistry, pharmacology, and use in traditional and modern medicine. Springer, Berlin, Germany. p 113.

5. Shin KH, Kim ON, Woo WS. 1988. Effect of the constituents of Angelica dahurica Radix on hepatic drug metabolizing enzyme activity. Kor J Pharmacogn 19: 19-27.

6. Lechner D, Stavri M, Oluwatuyi M, Pereda-Miranda R, Gibbons S. 2004. The anti-staphylococcal activity of Angelica dahurica (Bai Zhi). Phytochemistry 64: 331-335.

7. Kim CM, Heo MY, Kim HP, Sin KS, Pachaly P. 1991.
Pharmacological activities of water extracts of Umbelliferae plants. Arch Pharm Res 14: 87-92.

8. Saiki Y, Morinaga K, Okegawa O, Sakai S, Amaya Y, Ueno A, Fukushima S. 1971. On the coumarins of the root Angelica dahurica Benth, et Hook. Yakugaku Zasshi 91: 1313-1317.

9. Wang NH, Yoshiazaki K, Baba K. 2001. Seven new bifuranocoumarins, dahuribirin A-G, from Japanese Bai Zhi. Chem Pharm Bull 49: 1085-1088.

10. Kwon YS, Shin SJ, Kim MJ, Kim CM. 2002. A new coumarin from the stem of Angelica dahurica. Arch Pharm Res 25: 53-56.

11. Yang B, Wang JS, Zhao MM, Liu Y, Wang W, Jiang YM. 2006. Identification of polysaccharides from pericarp tissues of litchi (Litchi chinensis Sonn.) fruit in relation to their antioxidant activities. Carbohydrate Res 341: 634638.

12. Chang WS, Chang YH, Lu Fj, Chiang HC. 1994. Inhibitory effects of phenolics on xanthine oxidase. Anticancer Res 14: 501-506.

13. Yen GC, Chen HY. 1995. Antioxidant activity of various tea extracts in relation to their antimutagenicity. J Agric Food Chem 43: 27-32.

14. De Souza LC, De Araujo SM, De Oliveira Imbroisi D. 2004. Determination of the free radical scavenging activity of dihydropyran-2,4-diones. Bioorg Med Chem Lett 14: 5859-5861.

15. Pike J, Chandra RK. 1995. Effect of vitamin and trace element supplementation on immune indices in healthy elderly. Int $J$ Vitam Nutr Res 65: 117-120.

16. Halliwell B. 1996. Antioxidants in human health and disease. Annu Rev Nutr 16: 33-50.

17. Yokozawa T, Chen CP, Dong E, Tanaka T, Nonaka GI, Nishioka I. 1998. Study on the inhibitory effect of tannins and flavonoids against the 1,1-diphenyl-2-picrylhydrazyl radical. Biochem Pharmacol 56: 213-222.

18. Chiang HC, Lo YJ, Lu FJ. 1994. Xanthine oxidase inhibitors from the leaves of Alsophila spinulosa (Hook) Tryon. J Enzyme Inhib 8: 61-71.

19. Cos P, Ying L, Calomme M, Hu JP, Cimanga K, Van Poel B, Pieters L, Vlietinck AJ, Berghe DV. 1998. Structure-activity relationship and classification of flavonoids as inhibitors of xanthine oxidase and superoxide scavengers. J Nat Prod 61: 71-76.

20. Goodman Gilman A, Wall TW, Nies AS, Taylor P. 1990. Pharmacological basis of therapeutics (eighth edition). McGraw-Hill, New York, USA. p 674-681.

21. Piao XL, Park IH, Baek SH, Kim HY, Park MK, Park JH. 2004. Antioxidative activity of furanocoumarins isolated from Angelicae dahurica. J Ethnopharmacol 93: 243-246.

(Received January 19, 2011; Accepted February 18, 2011) 